\title{
Finglisches Cement.
}

Die quantitative Analyse eines englischen Cements, ausgeführt von Dr. Fr. P faff, ergab folgende Zahlen für 100 Theile:

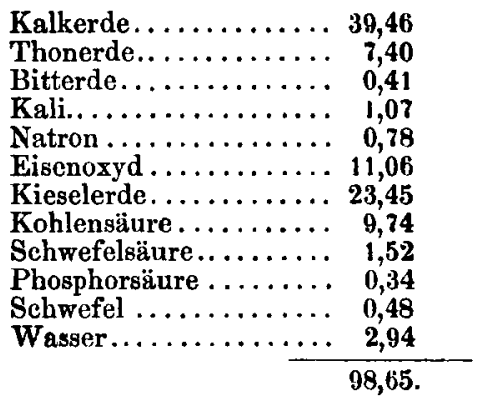

(Annal.der Chem. u. Pharm. XIII. 218.)

G.

\section{Untersuchungen über die Beständigkeit des hydrau- lischen Kalkes und der Cemente gegen die Wir- kung des Meerwassers.}

Malaguti's und Durocher's angestellte Beobachtungen über die Einwirkung des Meerwassers auf den Mörtel beweisen, dass diese viel verwickelter ist, als man denkt. Angestellte Analysen zeigen, dass diese Wirkung nicht ein und dieselbe ist, denn die dabei vorkommende Substitution der Talkerde für Kalk, welche man meist als eine Ursache der Veränderung des Mörtels bezeichnet, findet keineswegs immer statt, überdies ist diese Substitution nur partiell und, da sie von einer Aufnahme von Kohlensäure begleitet ist, so besteht ein solcher umgewandelter Mörtel in einem Thonerdehydrosilicate und einem dolomitähnlich gewordenen Carbonate. Oftmals verschwindet aber der Kalk ohne Substitution von Talkerde, und dann ist das Verhalten im Meerwasser gerade ebenso, wie in kohlensäurehaltigem süssen Wasser.

Bei den Umwandlungen eines mittelmässigen hydraulischen Mörtels theilen sich die Elemente desselben in zwei Verbindungen, die eine ist reich an erdigem Carbonate, die andere an Thonerle, und bildet einen schneeähnlichen Beschlag auf der Oberfläche des Mörtels. Diese Umwandlung findet nur langsam in den Mörteln und Cementen statt, die sehr hart sind. 